\title{
ROL DEL CONVENIO COLECTIVO DE LA ECONOMIA NACIONAL
}

\author{
Mario Pasco Cosmópolis
}

Marco Teórico

La negociación colectiva y su resultado: la convención o convenio colectivo, son reconocidos hoy en día como instrumentos indispensables de las relaciones laborales, pilares del Derecho Colectivo del Trabajo.

El Derecho Laboral, como todo derecho, tiene su asiento en la ley, en la norma of icial. El Derecho Laboral, sin embargo, tiene una "fuente autónoma de derecho objetivo" (1), una capacidad jurisgénica que no deriva de la colectividad legislativa del Estado sino de la voluntad de los particulares, de trabajadores y empleadores concretamente. Los convenios a que éstos arriban no están limitados por los marcos naturales de un contrato sino que los desbordan y trascienden; una vez concertados, no se someten a la voluntad de las partes sino que la subordinan; no se comportan, en suma, como un acuerdo privado -que tal son, en la forma- sino que se asemejan por sus efectos a una ley, en tanto que norma abstracta, general y obligatoria.

"Cuerpo de contrato y espíritu de ley", lo definió incomparablemente el gran maestro CARNELUTTI. "Centauro Jurídico", lo caracteriza metafóricamente RUSSOMANO. "Sirena" dice, con una sonrisa en los labios, MARTINS CATHARINO.

Contrato y ley al mismo tiempo - lo uno por su forma y lo otro por su fuerza vinculante-, el convenio colectivo confiere al Derecho Laboral una expansividad y una dinámica que permiten

(1) "Fuente de derecho extra-etática, típicamente laboral', la llama ERMIDA URIARTE, Oscar: "Formas de acción gremial en la empresa" ponencia al VIII Congreso Iberoamericano, Buenos Aires, 1983.- P. 565. 
hacer de la ley en sentido formal sólo un piso, un punto de partida, el mínimo de derechos y garantias de que es acreedor el trabajador frente a su patrono, en tanto que la plenitud de esos derechos y garantías no vendrá dada por la ley sino por la convención; que no es, sin embargo, un techo sino sólo un nuevo piso, más elevado, sobre el cual se construye la relación individual de trabajo.

La convención colectiva y su fuente generatriz: la negociación colectiva, constituyen fenómenos de indudable importancia jurídica y social, pero también, por cierto, económica. En esta ponencia remarcaremos precisamente este vector (2). Pero antes de ello es necesario definir algunos conceptos, enmarcar teóricamente el instituto.

\section{Definición y Caracteres}

La convención colectiva ha sido definida por la OIT en su Recomendación 91 como "todo acuerdo escrito relativo a las condiciones de trabajo y de empleo celebrado entre un empleador, un grupo de empleadores o una o varias organizaciones de empleadores, por una parte, y por otra, una o varias organizaciones representativas de trabajadores o, en ausencia de tales organizaciones, representantes de los trabajadores interesados, debidamente elegidos y autorizados por estos últimos, de acuerdo con la legislación nacional".

Esta definición apunta al concepto más amplio y engloba todos los otros nombres con que es conocida tales como convenio o contrato colectivo, contrato normativo, convenio de empresa, pacto normativo, contrato sindical, acta transaccional y mu-

(2) En ajuste al tema específico de la ponencia, debemos priorizar el rol 'económico' del convenio: incrementar los salarios y mejorar las condiciones de trabajo; más sin desconocer sus otras, trascendentes funciones como medio de solución de conflictos, como signo de equilibrio social y como instrumento de paz laboral, más aun si a través de estas funciones cumple también un rol económico.- Vid ERMIDA: Ibid., P. 567; y DE BUEN, Néstor: "Derecho del Trabajo', Porrúa, México 1979. T. II. P. 695. 
chos otros más, aunque en algunos países puedan tener ámbito o contenido distinto (3).

La convención o convenio colectivo aspira al establecimiento de normas convencionales de cumplimiento obligatorio, alcance muy expansivo y carácter inderogable, que impidan la discriminación o el favoritismo y permitan el trato igualitario a todos los trabajadores. A tal fin, tanto conceptual como dogmáticamente, la convención se ha desprendido de concepciones contractualistas que podían circunscribir sus efectos al marco reducido de las partes intervinientes, pues las reglas que de aquélla derivan habrán de regir imperativamente sobre relaciones de carácter individual, imponiéndose sobre éstas y privando a las partes de autonomía volitiva. Ello se da a través de los efectos que la convención procura, y que son:

Vigencia inmediata o automática:

Cuando el convenio inicia su vigencia, sus cláusulas normativas resultan obligatorias de modo instantáneo y automático para todas las empresas y trabajadores comprendidos en su alcance, sin necesidad de que se incorporen, en virtud de nuevos actos formales, a cada contrato individual ni de que sean ratificadas o reconocidas por los sujetos individuales cuyas relaciones van a regir (4).

(3) Con apenas diferencias de matiz, es la definición que adoptan las legislaciones de toda la Región: Art. 54 CT de Costa Rica, Art. 205 CT de Ecuador, Art. 22 CT de Guatemala, Art. 53 CT de Honduras, Art. 398 de Panamá, Art. 2 D.S. 006-71-TR de Perú, Art. 92 CT de R. Dominicana, aunque con variantes terminológicas muy acentuadas y la particularidad de que sólo Honduras y Perú autorizan la negociación extrasindical o de coalición. Vid. MURGAS TORRAZZA, Rolando: "Ano' taciones sobre la negociación colectiva de trabajo", en "Estudios Laborales", Panamá 1982 . P. 144 y ss.

(4) El Código del Trabajo de Guatemala lo expresa con claridad en su artículo 50 al establecer: "El pacto colectivo de condiciones de trabajo tiene carácter de ley profesional y a sus normas deben adaptarse todos los contratos individuales o colectivos existentes o que luego se realicen en las empresas, industrias o regiones que afecte". 


\section{Expansividad:}

El convenio no restringe sus efectos a los empresarios y trabajadores que forman parte de las organizaciones contratantes, sino que los extiende a todos los miembros de la respectiva categoría, sean o no miembros de aquélla y aunque a la fecha de suscripción del instrumento pudieran pertenecer o no a dicha categoría pero incorporarse posteriormente.

Este efecto erga omnes es muy nítido en los convenios de industria, aunque no siempre viene invívito en el convenio sino que requiere a veces de un acto gubernamental de extensión, sea mediante la homologación, sea a través de los denominados contratos-ley.

En sentido inverso a la expansividad, o sea la exclusión de grupos o sectores de los alcances de un convenio, el Código de Trabajo de Ecuador como el de Panamá y la legislación peruana separan de plano o permiten la segregación de los altos empleados o trabajadores de confianza. La limitación de un convenio a sólo el personal sindicalizado está, en cambio, definitivamente superada pues sólo subsistía en la legislación de Nicaragua, en tanto que en los demás países que tenían disposiciones semejantes ha perdido en lo absoluto toda vigencia, y en Panamá está expresamente prohibida.

\section{Inderogabilidad:}

En íntima conexión con la vigencia automática y expansiva del convenio está su vigencia incondicionada. Sus estipulaciones no pueden ser dejadas sin efecto por acto o contrato individual, son inderogables.

Tal efecto es incuestionable ante una derogación in peius; las legislaciones culminan de nulidad cualquier acuerdo particular que consagre para un trabajador derechos inferiores a los que emanan del convenio colectivo; v.g.: el decreto supremo 006-71-TR del Perú, los Arts. 406 y 408 del Código del Trabajo de Panamá.

La derogación in melius es en cambio admitida expresa o 
tácitamente por esas mismas leyes: no es inválida y, antes bien, está autorizada la pactación individual que mejora las condiciones vigentes de carácter colectivo.

\section{Retroactividad}

Algunos países - no todos- consagran que una nueva convención surte efectos desde que concluye la vigencia de la anterior, aunque haya sido formalizada con posterioridad a tal fecha; en otras palabras, que actúa retroactivamente.

En principio, nada se opone a esa retroactividad cuando el convenio se entabla a nivel de empresa; tampoco, a cualquier nivel, tratándose de las cláusulas obligacionales, dado que en ambos casos la acción se produce en términos propiamente contractuales, interpartes.

Caso distinto se da con los contratos de acción expansiva; su retroacción entraría en pugna con la irretroactividad de las leyes, que normalmente tiene rango constitucional, pues ino es acaso ese tipo de convenio una ley en sentido material?

La tesis es rebatida por GARZON FERREYRA (5) en términos rotundos: "El principio de irretroactividad de las leyes no es absoluto. El Derecho Colectivo del Trabajo, concepción jurídica imprevista en los cánones del derecho privado romanista, se rige por principios propios, diferentes y a veces opuestos a los tradicionales conceptos del Derecho Civil: La institución en examen, por ejemplo, escapa a cualquiera de los moldes clásicos del contrato civil. En el caso de la retroactividad de las cláusulas económicas, se pretende la reparación de la injusta remuneración de los trabajadores, reconociéndoles lo insuficiente de la retribución pagada por tareas prestadas, y por tanto, corresponde retribuir esa diferencia a fin de pagar el salario justo".

(5) GARZON FERREYRA, Ignacio: "El convenio colectivo: Publicación, divulgación, fecha de vigencia, retroactividad, plazo de duración", en "Derecho Colectivo Laboral", Buenos Aires, 1979.- P. 141. 
Dimensión Cualitativa. La Unidad de Negociación :

La unidad de negociación define el ámbito funcional de vigencia de la contratación colectiva, sus alcances en lo personal, material y territorial.

"A grandes rasgos, las dos modalidades usuales son las de empresa o establecimiento y las de industria o rama de actividad. En las primeras, el ámbito de vigencia se limita a los trabajadores que laboran para un solo empleador, cuya homogeneidad deriva de su común relación con un mismo patrono. En las industriales, los alcances sobrepasan dicho marco restringido y se aplican a todos los trabajadores de empresas de una similar actividad, con prescindencia de la tarea individual y aunque no exista entre los empleadores involucrados ningún género de relación, salvo su común actividad. Poco usuales y con tendencia a desaparecer son las unidades gremiales" (6). Como expresa RODRIGUEZ PIÑERO, "hoy es un hecho, subrayado por la sociología del Trabajo, que el trabajador está más afecto y ligado a la empresa y rama en la que trabaja que a su oficic o actividad personal" (7).

En toda América Latina - con la notoria excepción de Argentina, Brasil y, en cierta medida Venezuela- prevalece en forma abrumadora la negociación a nivel de empresa. Así acontece en Colombia, Costa Rica, Ecuador, Guatemala, Honduras, Panamá, Perú, Puerto Rico, República Dominicana y muchos otros países.

(6) PASCO COSMOPOLIS, Mario: "Negociación Colectiva en Iberoamérica", ARI, Lima 1979.- P. 21.

(7) RODRIGUEZ PIÑERO, Miguel: "La Unidad de negociación del convenio colectivo de trabajo", en "Derecho colectivo laboral", P. 331.Una tercera dimensión aparece con la llamada "Concertación social" que centraliza y globaliza la negociación en su más alto nivel, en la cúspide misma de las organizaciones a través de los "convenios-marco" o "cuadro" o "interconfederales". 
Comenta al respecto ARTURO S. BRONSTEIN (8): "Esta preferencia se explica por una serie de razones de tipo económico, histórico y político: El carácter de enclave que tuvieron las unidades económicas de cierto dinamismo durante los primeros decenios de este siglo; la tendencia de los trabajadores a constituir sindicatos de empresa, muchas veces estimulada por la legislación, aunque en otros casos ésta se limitó a reconocer una situación de facto; la gran disparidad de las empresas de un mismo sector industrial, lo que dificulta el establecimiento de reglas comunes, y el hecho de que el conflicto fue casi siempre anterior a la negociación, y a nivel de empresas. Por lo tanto, no debe sorprender que los primeros convenios colectivos se hayan celebrado precisamente en esos enclaves, al nivel de empresa, y por lo general luego de conflictos más o menos largos".

A lo que agrega: “¿Cuál es la situación actual? En líneas generales puede decirse que ha habido cambios cualitativos y se insinúa una tendencia a diversificar los niveles de la negociación, pero no se ha dado un vuelco cualificativo ni existen razones para presumir que se producirá en un futuro más o menos próximo. / Eso no quiere decir que la negociación a ese nivel (industria) sea desconocida:. . . En el Perú se ha negociado al nivel sectorial en ciertas ramas de actividades económicas, en particular de los bancos, las panaderías, las estaciones de servicio, y sobre todo el sector textil. . . En Panamá existen sendos convenios colectivos sectoriales para los talleres gráficos y de construcción. / Sin duda es en Venezuela donde más se ha avanzado en el tránsito desde la negociación por empresa hacia la negociación por industria" (9).

El ámbito funcional de vigencia del convenio colectivo resulta decisivo para cuantificar sus efectos. Es al mismo tiempo, en América Latina, una medida del desarrollo sindical y social: no es por acaso que en los países de mayor desarrollo relativo - Argentina y Brasil- prevalezca una modalidad, y otra en los demás; hay, por el contrario, una directa y causal relación entre un hecho y el otro.

(8) BRONSTEIN, Arturo S.: "La negociación colectiva", en "Las relaciones colectivas de trabajo en A mérica Latina", OIT, Ginebra 1981.- P. 92.

(9) BRONSTEIN : Ibid., P. 93-94. 


\section{El Sector Público}

Lo dicho líneas arriba corresponde, en general, al sector privado. Un nuevo y diferente capítulo se abre cuando nos referimos al sector público.

En algunos países, como en el Perú y República Dominicana, las empresas del Estado son asimiladas en su tratamiento laboral al conjunto del sector privado; en lo legal, en lo estadístico, en lo económico, a ese importante sector de la economía se lo trata como un todo con la actividad privada. En otros - Guatemala, Panamá- el sector productivo del Estado es asimilado a la actividad pública. Ello determina que las cifras estadísticas resulten heterogéneas $\mathrm{y}$ hasta incompatibles de pais a país.

Por otra parte, la incorporación de los servidores del Estado a los derechos colectivos de sindicación, negociación colectiva y huelga dista mucho de ser general, y aun en los paises en que se admite no está muy desarrollada.

No obst te en el Perú, a raíz de la promulgación de la Constitución Polí.:a de 1979, que ratificó además el Convenio 151 de la OIT, se har reconocido a los servidores públicos los derechos de sindicalización y huelga; entre 1982 y 1985 han quedado oficialmente registrados 113 sindicatos de servidores públicos, con un total de afiliados de 189,302. La comparación de cifras entre los sectores público y privado (incluidas en éste las empresas del Estado) reflejan que en el primero de ellos había, en 1986, 114 sindicatos registrados con aproximadamente 190.000 afiliados; en el sector privado, 4.800 sindicatos con 670.000 afiliados en cifras redondas.

En Panamá, como en Costa Rica, Guatemala y República Dominicana, en cambio, no les son reconocidos derechos colectivos a los trabajadores del Estado.

La Dimensión Cuantitativa. Presencia Real de la Negociación:

No obstante la gran difusión que la negociación colectiva ha adquirido en toda la Región en las últimas décadas, no es ni mucho 
menos un mecanismo universal. BRONSTEIN (10) destaca que el crecimiento a partir de 1970 ha sido muy rápido y en algunos casos impresionante, en especial en América Central (Honduras y Panamá), asi como en Ecuador y Perú.

En Honduras, de 18 convenios negociados en 1972 se pasa a 244 en 1979; en Panamá, de 74 a 168 en igual período; en el Perú, de 868 a 1,327, con una cobertura de 350,000 trabajadores. En este último país, el último quinquenio (1980-85), con la irrupción del sector público, se estiman en 870,700 los trabajadores sindicalizados, que representan el $39 \%$ del total de trabajadores asalariados y el 17.5\% del total de la PEA ocupada a nivel nacional; la negociación colectiva sólo alcanza al 6\% de la PEA (11).

Deben destacarse en relación con estos aspectos cuantitativos algunos comentarios específicos: el primero atañe al evidente paralelismo entre el desarrollo sindical y la negociación. Esta no es un fenómeno aislado, sino, antes bien, una consecuencia, un correlato o un acompañante necesario de aquél. Es relativamente sencillo establecer una relación de directa causalidad y proporción entre la difusión del sindicalismo y la contratación colectiva, habida cuenta además de que la negociación es normalmente la actividad preponderante y prioritaria del quehacer sindical.

Otro aspecto es el que se refiere a la estadística en sí, que muchas veces no distingue los convenios en razón de su importancia o magnitud, sino que registra únicamente el aspecto numérico. De esta forma, un importante convenio por rama de actividad, que involucra a miles de personas a nivel nacional y que tiene profundo impacto en la vida social y económica, aparece confundido con decenas de pequeñas convenciones de empresa, de ámbito muy restringido y nula trascendencia.

Es este un aspecto de enorme importancia, porque, de otro lado, no puede desdeñarse el impacto de la negociación colectiva

(10) BRONSTEIN : Ibid., P. 85.

(11) YEPEZ DEL CASTILLO, Isabel y BERNEDO ALVAREZ, Jorge: " $L a$ sindicalización en el Perú", Fund. Eberth, Lima 1985. 
en función a su escasa difusión cuantitativa. Esta escasa difusión es un hecho innegable; pero resulta innegable también que la misma se da en los sectores más modernos de la economía y en las empresas que generan la porción más significativa del PBI; su peso en la vida económica nacional es más gravitante. En el Perú "el 5\% de las empresas mueve el $80 \%$ del capital, y cuenta con el $10 \%$ de los trabajadores, que constituyen la fuerza laboral sindicalizada capaz de ejercer presión política y social para lograr reivindicaciones salariales" (12).

"En realidad -como dice BRONSTEIN (13)- ... más que la naturaleza pública o privada de la empresa, e incluso más que su productividad o su prosperidad económica, influye (...) su importancia vital en la economía nacional".

\section{El Ambito Material. El Contenido del Convenio}

\section{El Contenido Abstracto:}

El contenido de una convención colectiva corresponde a cuatro tipos de cláusulas, según tipología casi universal que resume DE LA CUEVA: la envoltura, las cláusulas normativas, las cláusulas obligacionales y las de coyuntura (14).

(12) GRADOS BERTORINI, Alfonso: "Burocracia y solidaridad en un pais en desarrollo", M. de Trabajo y P.S., Lima 1982...

(13) BRONSTEIN: Ob. cit., P. 96.

(14) La envoltura no es más que el recipiente formal: determinación de los sujetos intervinientes, los sujetos obligados, el ámbito material, territorial y temporal, $y$, en fin, los datos fácticos que encuadran la vigencia del convenio. Las cláusulas coyunturales son acuerdos efímeros en el tiempo que, una vez cumplidos o ejecutados, se extinguen: la construcción de una sala-cuna, el equipamiento de un comedor, la realización de un acto material concreto. Las cláusulas obligacionales contienen las obligaciones y derechos que recíprocamente adquieren las partes que directamente celebran la convención. No muy distinta es la clasificación que adopta la OIT al señalar cláusulas "introductorias" (que equivalen a las de envoltura), "ocasionales o eventuales" (coyunturales), "Contractuales" (obligacionales) y naturalmente "normativas", a las que agrega las cláusulas "programáticas" que constituyen una declaración de intención de las partes' se declara, por ejemplo, que es intención de las partes 
El elemento normativo es la esencia, la razón de ser, la entraña viva de la convención, a cuyo servicio se ponen las otras cláusulas obligacionales y de envoltura.

Las cláusulas normativas son la convención. Mediante ellas se modifican todos y cada uno de los contratos individuales de los trabajadores por ellas regidos, al actuar la convención como una ley en sentido material. El elemento normativo define el conjunto de condiciones a las que habrán de sujetarse en lo sucesivo los contratos individuales de trabajo de las personas a quienes aquel se refiere y está compuesto, según DE LA CUEVA (15), "por dos series de cláusulas que pueden denominarse, respectivamente, condiciones individuales para la prestación de los servicios y condiciones colectivas para la prestación de los servicios. Las dos series persiguen la misma finalidad, obtener mejores condiciones de trabajo para los obreros.

que el convenio "sea el instrumenlo idóneo para estimular y promover mejores condiciones morales, económicas y culturales... y promover la paz social durante su vigencia". Vid. DE LA CUEVA, Mario: "Derecho Mexicano del Trabajo", Porrúa México, 1963, T. II; y OIT: "La negociación colectiva en A mérica Latina”, Ginebra 1978.- P. 38.

(15) DE LA CUEVA : Ibid., T. II, P. 598.- Helios SARTHOU: "El objeto de los convenios colectivos de trabajo", en "Anales del Foro" 43-44, Montevideo 1983.- P. 36.- Distingue cuatro tipos de cláusulas normativas: 1) constitutivas del contenido de los contratos individuales; 2) de celebración, vigencia y extinción de los contratos individuales; 3) sobre la posición del trabajador en la empresa como organización social y de trabajo; y, 4) sobre instituciones conjuntas de las partes en el convenio.José MONTENEGRO BACA "Situación actual en el Perú de la negociación colectiva", en "La intervención del Estado en las relaciones industriales en la década de los 80', I Encuentro Iberoamericano sobre relaciones de trabajo, IES, Madrid 1980.- P. 286 denomina "objetivas o nucleares" a las cláusulas normativas - 'el alma de los convenios colectivos'- y distingue las siguientes clases: a) por la retribución del trabajo; b) por las modalidades de prestación del trabajo; c) por la terminación del contrato de trabajo;d) por la exclusión y preferencia sindical; e) por lo que ordenan: positivas y negativas; f) por la importancia del problema que norman: principales y accesorias; $g$ ) por la organización social de la empresa; $h$ ) por su alcance territorial: locales regirnales, nacionales; multinacionales e internacirnales. 


\section{El Contenido Concreto:}

Tan interesante como la clasificación teórica pero más trascendente en sus consecuencias prácticas es examinar el contenido material de las diversas cláusulas, vale decir, las materias usualmente negociadas.

Gran influencia tiene a este respecto la legislación laboral común, de cuya extensión y detallismo depende en mucho el contenido de los convenios. Se sostiene que en los países cuya legislación traza sólo los grandes lineamientos de una política laboral, la negociación colectiva se ve estimulada en la necesidad de llenar la gran cantidad de vacíos normativos; en cambio, leyes muy reglamentaristas limitan el campo de acción negociadora. "La importancia jurídica de la negociación colectiva es mayor o menor en razón inversa de la intensidad y de la extensión del derecho positivo de cada nación, material e instrumental o procesal", expresa al respecto MARTINS CATHARINO (16).

Hay también, a veces, formas de intervención legislativa más directas, por lo general negativas: limitaciones, restricciones, interferencias y hasta prohibiciones, a consecuencia de crisis económicas, tendencias político-ideológicas, convulsiones sociales, o todo ello a la vez.

En Panamá la negociación colectiva estuvo suspendida durante dos años (1976 a 1978). En el Perú, durante varios años estuvo constreñida a un único punto, el aumento salarial; en la actualidad (1987), un decreto supremo establece la forma de computar un reajuste automático de salarios al vencimiento del 6 to. mes de vigencia de una convención, lo que debe hacerse mediante la aplicación directa del índice de crecimiento de los precios al consumidor.

Ahora bien, con referencia específica a las materias usualmente negociadas, la constatación más asidua es el contenido salarial de toda convención, lo cual no debe mover a la menor sorpresa.

(16) MARTINS CATHARINO, José: "Perspectiva de la negociación colectiva en América Latina", En Derecho Laboral No. 125 Montevideo, enero-marzo 1982.- P. 41. 
Precisa al respecto la OIT (17) que las "cuestiones de salarios $y$ condiciones de trabajo constituyen el núcleo del convenio y suscitan siempre el interés de los trabajadores"; y AMERICO PLA RODRIGUEZ, el gran maestro uruguayo, es aún más enfático cuando dice que "la médula de las relaciones industriales es la fijación del salario y las condiciones de trabajo por medio de la negociación colectiva" (18).

Un acucioso estudio del "Programa Internacional para el mejoramiento de las condiciones y medio ambiente de trabajo" de la OIT (cuyas siglas en francés son "PIACT"), con referencia a Panamá, en el que se examinaron 68 de las 126 convenciones celebradas en 1980, revela que en todas ellas sin excepción se llegó a acuerdos sobre aumentos salariales, ya sea a través de cláusulas que establecen aumentos escalonados para ser otorgados en el lapso de la duración de la convención colectiva, o según la antigüedad del trabajador, el lugar de trabajo, el monto de los salarios o a cuenta de futuros reajustes salariales ordenados por ley, asi como aumentos específicos para los trabajadores remunerados con comisión y para otras categorías ocupacionales. Además se establecen clasificaciones de puestos y se fijan salarios mínimos e iniciales y se conviene en proceder a revisión de salarios durante la vigencia de la convención cuando ésta tiene una duración superior a dos años.

En el Perú, las convenciones colectivas rara vez son un conjunto estructurado y orgánico de normas sino, por el contrario, una serie dispersa e inconexa de beneficios de lo más variados, entre los que descuella nítidamente el aspecto salarial. Otras cláusulas tienen que ver con las condiciones de trabajo y con prestaciones de corte asistencial y de previsión social (19).

(17) OIT: 'La negociación colectiva. ., ", P. 39.

(18) PLA RODRIGUEZ, Américo: "El papel del Estado en las relaciones industriales en la década de los 80", en "La intervención del Estado .'-P. 329.

(19) La revista "ANALISIS LABORAL" No. 106, Lima, marzo 1986 señala, entre otras, las siguientes cláusulas de 'seguridad social' en la negociación colectiva peruana: asignaciones por nacimiento de hijo, por sala cuna, por matrimonio, de sangre y equipo transfusor, familiar, para medicinas y atención médica, por fallecimiento del trabajador, padres, hijos, 
Destaca y sintetiza muy bien esta situación TIZIANO TREU (20) quien reporta que en muchos países las cláusulas 'cuantitativas' (económicas) prevalecen sobre una negociación cualitativa (por ejemplo, sobre calidad de vida laboral, estabilidad laboral, reestructuración industrial e innovaciones técnicas), al contrario de lo que sucede en los países 'desarrollados'.

\section{Características de la Negociación Colectiva en la Región}

No obstante las naturales y a veces sustanciales diferencias de un país al otro, es posible discernir ciertos caracteres comunes o, al menos, predominantes en la región examinada. A grandes trazos la negociación colectiva presenta el perfil siguiente:

\section{Es ampliamente descentralizada:}

Con contadas excepciones, la contratación -según ya se ha señalado- se verifica a nivel de la empresa o establecimiento; rara vez con carácter general para toda una industria o actividad; y nunca con alcance global o universal.

De otro lado, en los contados casos de negociación por rama no hay articulación a nivel inferior a través de convenios complementarios en las unidades de producción. Es decir que cuando se negocia por rama de actividad, ese convenio representa la única forma y el único nivel de pactación.

Y como quiera que la concertación social es en la región sólo una perspectiva incipiente, mucho más desarrollada a nivel hipotético y teórico que de manifestaciones reales y concretas, podemos concluir que no hay la más mínima tendencia a la concentración ni a la articulación.

esposa, hermanos menores; pago de consulta médica para familiares; crédito en farmacia; descanso por lactancia; permiso por fallecimiento de un familiar; seguro de vida; etc.

(20) TREU, Tiziano: "Procedures and structures of collective bargaining at the enterprise and plant level", ponencia al XI Congreso Internacional, Caracas 1985, T.I., P. 45. 


\section{Es formalista}

La negociación, más que expresión de autonomía colectiva, se da como un proceso controlado por el Estado, subordinado a esquemas procesales más o menos estrictos, con grados diversos de intervencionismo oficial. El Estado provee no sólo un sólido soporte jurídico sino también una estructura administrativa encargada de supervisar, orientar y hasta conducir la negociación.

“En América Latina, la queja más común hace hincapié en la rigidez, el legalismo y la lentitud de los procedimientos de solución; . . . ello ha dado lugar en muchos países a un divorcio de facto entre los métodos formales y los métodos paralelos de solución. Otra queja se refiere a que el recurso sistemático a esos métodos de solución por terceros menoscaba el derecho de negociación colectiva bilateral. Otro motivo de crítica es la posible parcialidad de los órganos de solución, ya que a menudo estos carecen de independencia y obedecen directa o indirectamente a las autoridades públicas. Las tensiones más importantes se pueden originar en los sistemas cuyos métodos de solución de conflictos han sido concebidos de tal manera que el procedimiento parece conducir ineluctablemente hacia el arbitraje obligatorio" (21).

“Un ejemplo lo constituyen los sistemas 'lineales' de prevención y solución, aplicados sin imaginación ni adaptación a las cambiantes realidades - dice EMILIO MORGADO (22). En esos sistemas las instancias o etapas se recorren sin ánimo de llegar a acuerdos sino con el propósito de cumplir requisitos formales".

En prácticamente todos los paises examinados —con la sola excepción de Puerto Rico y Trinidad-Tobago, la negociación colectiva tiene un cauce procesal definido. En muchos de ellos, significativamente en el Perú, la negociación se eslabona de modo sucesivo con los demás medios de solución de conflictos (conciliación,

(21) OIT: "Relaciones de trabajo y desarrollo en las A méricas", Informe III a la XII Conferencia, Montreal 1986 de los Estados de América miembros de la OIT, Ginebra 1985.- P. 51.

(22) MORGADO, Emilio: "La actual crisis y los conflictos de trabajo en La. tinoamérica”, en Análisis Laboral 100, Lima, Oct. 1985.-P. 11. 
mediación, arbitraje), como etapas de un proceso continuo; previsto todo ello en normas legales de observancia obligatoria.

\section{Adolece de excesivo intervencionismo estatal:}

En inmediata y directa relación con lo anterior se dan formas más o menos intensas de intervención del Estado en la negociación. Hay países que respetan una cierta autonomía de las partes y paises que consagran grados exagerados de intervencionismo: entre los primeros, Ecuador, Puerto Rico, República Dominicana, Trinidad-Tobago; de los segundos y con mucho margen, Perú.(23)

Resalta al respecto la OIT que uno de los obstáculos que se oponen al desarrollo de la negociación colectiva en la Región es que ". . . el sistema de relaciones de trabajo, tal como ha sido concebido, privilegia las soluciones heterónomas fundamentalmente a través de la legislación; ... el procedimiento de negociación colectiva se confunde con el de solución de conflictos y este último conduce casi ineluctablemente al arbitraje obligatorio por las autoridades públicas" (24).

Tiene escasa difusión social:

La negociación colectiva, no obstante el acelerado desarrollo de los últimos lustros, sigue siendo un fenómeno fundamentalmente urbano; con escasas excepciones, no ha llegado a los estratos campesinos, salvo en los casos de plantaciones industrializadas.

Aun dentro de la ciudad, está lejos de abarcar al conjunto de la población trabajadora, concentrándose únicamente en la gran y

(23) En el Perú el intervencionismo estatal es agudo: nada funciona sino es a través de un mecanismo oficial. Así: para su validez, las convenciones requieren de aprobación por la autoridad administrativa de trabajo; ante el fracaso de la negociación (trato directo), debe recurrirse necesariamente a una junta de conciliación presidida por un funcionario; si no se alcanza resultado positivo en la conciliación, el caso es sometido a resolución obligatoria de la misma autoridad en una suerte de arbitraje compulsivo.

OIT: "Relaciones. . ", Informe III.- P. 24. 
mediana empresa. Estas - la mediana y gran empresa- no son, empero, empleadores masivos en términos del país; antes bien, en sociedades subdesarrolladas proliferan pequeños establecimientos de pocos trabajadores a los que no llega la sindicación y, por ende, tampoco la negociación.

\section{De limitado contenido material:}

Ya hemos examinado como la negociación dentro de la Región no responde, en general, a una política amplia de autonomía colectiva sino que se limita a unas cuantas materias especificas (salarios y condiciones de trabajo). Sólo resta agregar que no han llegado a nuestros países las discusiones, hoy en día tan vitales para el mundo desarrollado, sobre reconversión industrial, robotización, reducción del tiempo de trabajo, "work sharing", y otras de similar naturaleza.(25)

\section{Es marcadamente conflictual:}

"El proceso de negociación - dice JORGE FABREGA (26) con referencia a Panamá, pero en observación que vale para toda el área- se desenvuelve en forma eminentemente conflictiva. Los sectores obreros y los sectores empresariales ven en él todavía una confrontación de fuerzas más que un mecanismo de determinación racional de condiciones de trabajo. Proposición de peticiones injustificadas, en ocasiones, imposibles de satisfacer. Renuencias, igualmente injustificada, en otros casos, por parte de empresarios, en reconocer legítimas y viables aspiraciones".

La explicación histórica la encuentra EFREN CORDOVA (27) en una doble influencia exógena desfavorable: "De una parte, el movimiento sindical siguió el modelo francés de sindicalismo impugnador, impregnado de influencias ideológicas y de vocación

(25) Vid. TREU: Ob. cit. - P. 45.

(26) FABREGA, Jorge: “Las convenciones colectivas en Panamá, Panamá 1981.- P. 8.

(27) CORDOVA, Efrén: "Tendencias de las Relaciones Laborales en América Latina", en Análisis Laboral No. 100 (Lima, octubre de 1985); p. 8. 
extralaboral; de otra parte, se importó el modelo norteamericano de negociación que concibe ese proceso como una relación antagónica. Ni trabajadores ni empresarios tuvieron pues interés en fomentar programas de cooperación e integración".

\section{Condicionamientos}

¿Cuáles son, en términos amplios, los factores que han determinado el modelo de relaciones colectivas que impera en el área examinada?. O dicho de otro modo, ¿cuáles son los factores condicionantes?

Deben examinarse al respecto variables jurídico-legales, sociales, económicas y políticas que HERLIOS SARTHOU (28) sintetiza muy bien. "En los países del área del subdesarrollo (América Latina, Africa, Asia) el Derecho Colectivo cuando existe es restringido y débil en su implantación real como consecuencia de condiciones económicas estructurales. Mercados reducidos (de lo que es ejemplo la balcanización de América Latina), predominio del sector primario de servicios, dependencia como suministradores de materias primas y compradores de productos industrializados de los países desarrollados con la adición de causas políticas y líneas económicas que debilitan al sector trabajador, crean dificultades al desarrollo sindical cuestionándose en teoria y/o práctica los derechos emergentes del Derecho Colectivo del Trabajo".

\section{El entorno jurídico}

Ya está dicho pero interesa reiterar que la legislación $-\mathrm{y}$ con ella la globalidad del mundo jurídico-laboral- ejerce decisiva influencia en la concreción de un modelo determinado de instituciones. En lo material, de acuerdo al campo de cobertura y al grado de detalle al que llegue esa legislación, cuanto más exhaustiva, prolija y detallista sea, más estrecho será el margen para las materias negociables; a la inversa, a menor reglamentación mayor permisividad.

(28) SATHOU, Helios: "Perspectivas del Derecho Colectivo del Trabajo", en Derecho Laboral 123, Montevideo, julio-setiembre 1981.- P. 584. 
La legislación puede también imponer un determinado esquema $o$, aun sin previsión específica, inducirlo u orientarlo. La legislación peruana, por ejemplo, aunque menciona a los sindicatos de industrias, no prevé la forma de constituirlos; de similar manera, hace referencia a las convenciones por rama de actividad pero no contempla la forma de celebrarlas ni, lo que es más grave, sus alcances y efectos. La vida, que es más rica que la ley, ha permitido que unos y otras realmente existan, si bien limitadamente.

Caso exactamente inverso es el panameño. El Código de Trabajo de 1970 elevó a 50 el número mínimo de trabajadores necesario para constituir un sindicato. Ello, lejos de constituir una traba para la libertad sindical como aparentaría a primera vista, se ha traducido $-\mathrm{y}$ ésa fue la intención manifiesta del legislador-en un estímulo para que se creen sindicatos por rama y no por empresa.

Hay, finalmente, situaciones de coyuntura que en un momento dado pueden alentar o restringir la negociación. Esta estuvo suspendida por dos años en Panamá, y durante cinco, fuertemente limitada en el Perú.

\section{Lo político}

Indesligable de lo anterior, el impulso o freno políticos son muchas veces el factor de mayor peso.

"El Derecho Colectivo es estrechamente dependiente de las características autoritarias o democráticas del régimen político imperante. El Derecho Colectivo necesita de la democracia política para existir y desarrollarse. / Habitualmente, las periódicas y generalizadas rupturas del orden jurídico democrático en los países del Tercer Mundo incluyen entre sus medidas la anulación o suspensión indeterminada del ejercicio de las libertades que otorga y regula el Derecho Colectivo./ Esto es así en parte porque en el paquete de medidas del Gobierno de facto se incluye la estabilización salarial sobre la base de centrar en el ingreso salarial la causa de la espiral inflacionaria. Pero también porque la anulación de derecho o de hecho de las garantías del Derecho Colectivo busca 
sustraer al sindicalismo los medios jurídicos para la defensa del orden jurídico violado".(29)

\section{Lo social}

Dentro de este rubro queremos comprender dos grandes conceptos: el ámbito macro-social propiamente dicho; y el ámbito social-laboral.

En lo primero, la Región en estudio constituye el conjunto de países de menor desarrollo a nivel latinoamericano. He aquí algunas de las cifras más reveladoras: La PEA asalariada es alrededor de sólo el 50\% de la PEA total o aun inferior en Guatemala (47.2), Honduras (46.1), Ecuador (51.7), Perú (45.2) y República Dominicana (51.9). En la década de los $80^{\prime}, 4$ países del área tenían un PBI per cápita inferior a $\$ 1000$ por año, y prácticamente ninguno superior a $\$ 2000$ (Ver anexo estadístico).

Si el ámbito socio-laboral lo medimos a través de algunos indicadores tales como la tasa de sindicalización, el número de convenios colectivos, el total de trabajadores comprendidos en ellos y su posición relativa frente a la población total y la económicamente activa, las constataciones resultan virtualmente iguales, según vimos anteriormente.

\section{Condicionantes económicos}

"Desde el punto de vista económico, considerando que el núcleo de la 'negociación colectiva' está constituido por reivindicaciones de ventajas salariales que habrán de hacer más oneroso el costo de producción, el estado de la economía en la ocasión tiene gran importancia, positiva o negativa./ Por ejemplo, en una economía de mercado, con todas sus distorsiones (concurrencia imperfecta y monopolios), los empleadores resisten menos si les es posible trasladar el incremento en los costos a la masa de consumidores, de la cual los propios trabajadores constituyen expresivo contingente. Siendo posible este traslado, la negociación se facilita,

(29) SARTHOU: Ibid. - P. 585. 
pues, en última instancia, existe convergencia de intereses directos e inmediatos".(30)

Algunos caracteres ya señalados de la negociación colectiva en la Región también influyen y hasta condicionan su funcionamiento económico, en un doble sentido: en su concertación y en sus efectos. Tales caracteres son la escasa implantación cuantitativa, su presencia cualitativa y su ámbito o nivel prevalente, que es el de empresa o establecimiento.

Así, el convenio opera plenamente en las empresas más modernas, sofisticadas y rentables, como son el sector manufacturero, el sector servicios (especialmente turísticos, en Panamá, Puerto Rico y República Dominicana), el sector minero (en el Perú) y pesquero (en Ecuador y Perú), con la notable excepción del sector bancario panameño.

De este modo, los salarios y en general las prestaciones pactadas están permanentemente situadas muy por encima de la media nacional, regional y local. Hay una relación directa entre la 'calidad de la empresa' y el rango de las remuneraciones.

No siendo muchas numéricamente las empresas involucradas ni demasiado amplia su población laboral, son sin embargo las más grandes, poderosas e importantes, con una decisiva presencia en la formación del producto bruto nacional. La dimensión cuantitativa no guarda proporción con la desnivelante presencia y cualitativa, según ya vimos.

Las empresas capital-intensivas tienden a ser más abiertas a la concesión de altos salarios y prestaciones a todas las categorías de empleados, por la menor incidencia de la mano de obra en su estructura de costos. Igual sucede con las empresas que ocupan una posición monopólica u oligopólica, muchas veces multinacionales, en especial cuando disfrutan de un mercado cautivo.

Finalmente no puede ignorarse que el tipo de convenio predominante -el de empresa- acentúa la relación entre aquél y cier-

(30) MARTINS CATHARINO, José: Ob. cit.- P. 43. 
tos factores concomitantes como son la estructura interna de costos de la empresa, el grado de competencia externa, la productividad individual y colectiva, etc.

"La negociación por empresa beneficia a los sindicatos de empresas más fuertes, pero tiende a dejar al margen a los trabajadores de empresas o sectores difícilmente organizables. También permite que los salarios se fijen teniendo en cuenta las condiciones económicas de cada empresa, lo que, por un lado, preserva la competitividad de las empresas más frágiles pero, por otro, ahonda las diferencias entre distintos grupos de trabajadores".(31)

Son éstas concretamente algunas de las críticas que con más frecuencia se hacen a este tipo de contratación. "Se ha dicho que la generosidad de las prestaciones se traduce en mayores costos, mayores precios y mayor inflación. También se ha sostenido que los trabajadores mejor organizados y que disponen de mayor poder de negociación gozan de un status privilegiado con respecto a otros que no están en la misma situación y que con ello se tiende a crear una 'aristocracia obrera'" (32), pues se crean ". . . disparidades entre los salarios y condiciones de trabajo de los trabajadores de diferentes empresas, grandes o pequeñas, más prósperas o menos prósperas, con sindicatos más fuertes o menos fuertes, cosa que pudiera ser considerada como una situación objetivamente injusta y susceptible de romper la solidaridad entre los trabajadores. Su otro gran inconveniente es que sólo es posible, o sólo es apta para beneficiar a los trabajadores en las empresas comparativamente grandes, puesto que sólo en las mismas los sindicatos poseen un poder de negociación eficaz". (32)

En otro aspecto, el mercado de trabajo, su extensión y composición, su flexibilidad o rigidez, los grados de adiestramiento y capacitación de la mano de obra y otros factores semejantes influyen también en la contratación.

(31) OIT: "Relaciones. . ', Informe III.-P. 43.

(32) BRONSTEIN : "La negociación. .."-P. 96.

(33) BRONSTEIN, Arturo: "El nivel de la negociación colectiva: un enfoque comparativo", en Análisis Laboral 100, Lima, octubre 1985.- P. 19. 
La estabilidad laboral, por ejemplo, en los países donde existe provoca rigidez del mercado de trabajo, baja movilidad "(turn over") y, por efecto contrario, disminución de los niveles de empleo. En tales casos, las materias vinculadas a la protección de la estabilidad ya no aparecen en los convenios por ser innecesarias y hasta superfluas; proliferan, en cambio, las que acentúan la protección del trabajador empleado: bonificaciones al trabajo por turnos, en horas extras, etc., más que aquellas que pudiesen permitir la ampliación de los puestos de trabajo.

En el polo opuesto, donde no hay estabilidad son de la mayor importancia los reclamos sindicales que buscan establecerla convencionalmente. Ello no obstante, como hace notar WALKER ERRAZURIZ (34), ante la falta de tutela legal, en especial en situaciones de crisis, "... se suele producir que el empresario presiona indebidamente al trabajador con el fantasma del despido y lo obliga a modificar el contrato individual de trabajo para rebajar la remuneración"; y aunque el acento lo carga WALKER en lo individual, idéntica reflexión se debe aplicar mutatis mutandi en la contratación colectiva. (35)

La situación de pleno empleo o desempleo generalizado (caracterizados así, gruesamente, al solo efecto didáctico) desplaza el poder de negociación hacia los trabajadores en el primer caso, y hacia los empleadores en el segundo. Cuando la mano de obra escasea, los salarios tienden obviamente a subir; en tal caso, el convenio, a la par que responde a esa lógica de las cosas, actúa también, como freno a una competencia 'salvaje' entre empresas. Muy a la inversa, en épocas de desempleo agudo los aspectos salariales ceden ante la necesidad de preservar el puesto de trabajo; más

(34) WALKER ERRAZURIZ, Francisco: "La tutela de las relaciones laborales ante la crisis económica y financiera de la empresa", ponencia al VIII Congreso Iberoamericano, Buenos Aires 1983.- P. 20.

(35) La ley peruana, tan celosa en materia de estabilidad laboral, autoriza sin embargo, por excepción, la desmejora de los salarios y condiciones de trabajo por vía colectiva cuando se trata de enfrentar un desmedro económico o vicisitudes derivadas del caso fortuito o la fuerza mayor. 
importantes resultan las cláusulas de garantía que las propiamente económicas.(36)

La coyuntura económica es, finalmente, el condicionante mayor: la expansión económica suele ir acompañada de bonanza salarial, lo cual es apenas una simple consecuencia natural. La crisis, en cambio, abate los salarios. En toda la región examinada el decenio 1975-85 refleja una caída persistente y acentuada de los salarios reales. Algunos estudios en el Perú (37) llegan a establecer que, a partir de una base 100 en 1973, el salario real promedio (obreros) habría caído $56.9 \%$ para pasar a ser de $43.1 \%$; y el sueldo (empleados) a $49.7 \%$, con una pérdida de $50.3 \%$.

A la inversa, en el último año (1986), el Perú ha tenido un espectacular crecimiento de su PBI cercano al 9\%; los salarios han presentado también significativos avances: $11.4 \%$ el sueldo real (empleados) y $7.5 \%$ el salario obrero. (38)

A no dudarlo, la coyuntura económica es el mayor condicionante del contenido económico de las convenciones colectivas.

El Convenio Colectivo y sus efectos económicos y sociales

Dos son, de inmediato, los campos económicos hacia los que trasciende el convenio colectivo: la inflación y la productividad.

(36) Vid. DOMIJAN, Adolfo: "La convención colectiva de trabajo como resguardo en la continuidad de equilibradas y justas relaciones laborales en las crisis económicas que se producen en el estado moderno", ponencia al VIII Congreso Iberoamericano, Buenos Aires 1983.- P. 133.

(37) Cit. por CIUDAD, Adolfo: "Problemas del modelo peruano de las relaciones de trabajo", en Análisis Laboral 112, Lima octubre 1986.P. 21.

(38) Un reciente informe de DESCO: "Coyuntura Laboral", octubre-diciembre 1986, señala adicionalmente que el ingreso mínimo creció $3.6 \%$ y que la remuneración promedio de los no-sindicalizados osciló entre $(-4 \%)$ y el ritmo de la inflación mientras que "los trabajadores organizados y que celebran anualmente sus convenios colectivos han sido quienes consiguieron los mayores porcentajes de aumentos salariales". 
Ambas interaccionan, por lo demás, como variables fundamentales de una política de rentas o de redistribución de ingresos y en una más vasta dimensión, de una política económica.

En su rol de redistribución de ingresos se centra, en gran medida, su impacto social, a través del mejoramiento del nivel y de la calidad de vida y el establecimiento de prestaciones que suplan o complementen las que de modo insuficiente proporcionan los servicios públicos de previsión y seguridad social.

Al interior de la empresa, finalmente, el convenio colectivo puede actuar como instrumento favorable o desfavorable de la administración salarial, habida cuenta que los intereses y expectativas del empresario no coinciden y hasta divergen de los de sus trabajadores acerca del rol, el contenido y los objetivos del salario.

\section{Inflación}

Viene de antiguo la acusación de que el alza de los salarios es la fuente primaria de la inflación; alza que en muchos casos, como es natural, tiene como principal origen la contratación colectiva.

Algo de verdad y de razón puede tener la acusación, pero no toda. Hoy en día se advierte con claridad cómo es que son otros los factores macroeconómicos que pulsan sobre el crecimiento de los precios y generan la famosa espiral inflacionaria.

La OIT había desde tiempo atrás refutado la acusación al expresar que ". . . es tan válido sostener que los aumentos salariales desencadenan la inflación como lo contrario, es decir, que son los aumentos de precios los que obligan a los trabajadores a reclamar mejoras salariales. En otras palabras, los trabajadores son víctimas, y no causantes de la inflación. Por lo demás, la reducción de los salarios reales produce una caida en el consumo, lo que a su vez ocasiona a veces un descenso en el nivel de la producción".(39)

Políticas heterodoxas como el Plan Austral en Argentina, el

(39) OIT: “La negociación colectiva. .,", p. 50. 
Plan Cruzado en Brasil y el Programa del Presidente Alan García del Perú, vienen a darle la razón al haber obtenido éxito contra la inflación sin ir acompañadas de una contención salarial rígida. En el bando contrario, las recetas ortodoxas del Fondo Monetario Internacional se tradujeron en la mayoría de países -incluidos los tres mencionados - en una caída vertiginosa del salario real a la par que hiperinflaciones de 3 dígitos.

Es que, como dice LUPO HERNANDEZ RUEDA (40), "las especulaciones sobre la causa de la inflación son tan viejas como la historia de la teoría económica, y los diversos estudios académicos sobre la inflación, no obstante sus diversos matices y puntos de vista no han podido establecer en forma definitiva las causas de la inflación". A lo que agrega - con apoyo en MICHAEL PARKIN ("las demandas de salarios sólo han sido una parte del mecanismo que sostiene a la inflación, pero no su causa") y L.A. DICKSMIAREAUX ("es muy inseguro el efecto que es posible demostrar ejercen los salarios sobre los precios") que las causas de la inflación “... son complejas y no residen simplemente en las demandas de los trabajadores".

¿Dónde está la causa y dónde el efecto?. Dice la OIT: "En los países en vías de desarrollo, con inclusión de América Latina y el Caribe, se ha sostenido a menudo que la negociación colectiva creaba expectativas inflacionarias, no sólo por su incidencia sobre los salarios de los trabajadores que cubre directamente (que, como se ha visto son pocos), sino también por su efecto de arrastre sobre los ingresos de otros sectores. Sin embargo, este argumento no parece tener en cuenta que en dichos países la negociación colectiva ha servido sobre todo para reajustar los salarios después de la inflación, pero no antes de ésta, es decir, que se ha utilizado para que los trabajadores puedan recuperar parte del poder adquisitivo que perdieron como consecuencia de la erosión de la moneda, y no para mejorar los salarios en términos reales. En efecto, basta con examinar el comportamiento de las remuneraciones en periodos relativamente largos, de diez o quince años por ejemplo, para ob-

(40) HERNANDEZ RUEDA, Lupo: "Inflación y relaciones de trabajo: el compromiso social en los años 80", en II Encuentro Iberoamericano sobre Relaciones de Trabajo, IELSS, Madrid 1984.- P. 256. 
servar que en la mayor parte de los países el salario real de los trabajadores amparados por convenios colectivos en general ha resistido mejor que las remuneraciones de otros trabajadores a los embates de la inflación, pero que las mejoras efectivas del poder adquisitivo fueron mínimas, cuando no nulas o negativas. ..".(41)

HERNANDEZ RUEDA, en conexión con el problema del desempleo, argumenta en dirección similar: "La acción sindical por mejores condiciones de trabajo y más altos salarios obedece principalmente al alza creciente de los precios y del costo de vida, y estas demandas en los países en vías de desarrollo, donde existe un sindicalismo incipiente aunque generalmente militante, no son determinantes del alto índice de desempleo. El número de trabajadores organizados es muy reducido con relación a la población económicamente activa con empleo".(42)

"Es que pocos fenómenos de la vida contemporánea afectan tan hondamente a las relaciones obrero-patronales, el nivel de vida de la población trabajadora, la gestión de las empresas y la economía de un país como la inflación", dice categóricamente EFREN CORDOVA. "En el plano laboral la inflación introduce un elemento de incertidumbre en la conducción de la negociación colectiva, modifica a menudo las estructuras de negociación y el contenido mismo de los convenios y aumenta los índices de conflictividad". (43)

PLA RODRIGUEZ (44) refuta enfáticamente la "tendencia primaria de atribuir la principal responsabilidad en ese fenómeno (la inflación) al factor salarial", a la que califica de "equivocada". "Un autor griego-DIMITRIOS GERMIDIS-ha demostrado que sí puede haber una cuota de responsabilidad de los sindicatos en el progreso de la inflación por su reclamo de mayores salarios, esa

(41) OIT: "Relaciones. . ", Informe III.-P. 42.

(42) CORDOVA, Efrén: "La inflación y el Derecho del Trabajo", en Revista Relaciones de Trabajo 5, Valencia 1985.- P. 55.

(43) HERNANDEZ RUEDA: Ob. cit.-p. 257.

(44) PLA RODRIGUEZ: Ob. cit.-P. 331. 
responsabilidad es compartida por los empleadores (que no se resignan a reducir sus beneficios y que, por el contrario, pretenden acrecentarlos al mismo ritmo que los obreros), con los gobiernos (que siguen financiando la inflación a través de su política del gasto público y del crédito que deriva en un aumento de la moneda) y con los consumidores (que, gastando sus reservas o recurriendo al crédito, contribuyen a aceptar los nuevos precios). ( Pero además $-\mathrm{y}$ esto es mucho más profundo-, esa lucha por mejores salarios está impuesta por la sociedad de consumo, que es, por esencia, inflacionaria. Paradójicamente, se llama así a una sociedad en la que la labor productiva no se basa en las necesidades de los consumidores, sino, por el contrario, en el deseo de ganancia de los productores que planean su labor para obtener el mayor lucro posible y luego lo hacen consumir por medio de la propaganda y del aumento nominal de los salarios que, al traspasarlo a los costos, lo hace pagar por el consumidor. El modelo consumista es, naturalmente, inflacionario porque la necesidad individual tiende a predominar sobre la necesidad colectiva y lo superfluo sobre lo útil". Sabias palabras. Que son corroboradas por EFREN CORDOVA de modo no menos contundente: "Tiende a prevalecer en nuestros días la idea de que le negociación colectiva y el aumento salarial fungen más bien como agentes transmisores o comunicantes y que en vez de crear lo que hacen es perpetuar y a veces acelerar un proceso inflacionario. La aceleración es por supuesto mayor cuando los empleadores pueden transferir los aumentos de salarios al consumidor".(45)

En una demostración por vía inversa, es válido comprobar que la suspensión de la negociación colectiva como medida contrainflacionaria tampoco ha demostrado eficacia. "A este respecto -dice la OIT (46)- es mucho lo que se puede decir, en favor o en contra, desde un punto de vista meramente teórico. Sin embargo, en los países en desarrollo de las Américas los resultados prácticos parecen indicar que la suspensión de la negociación colectiva nunca ha sido por sí sola una medida suficiente para combatir la

(45) CORDOVA: La inflación. ..."- p. 61.

(46) OIT: "Relaciones. . "Informe III.- P. 41. 
inflación. De hecho, ciertos países que congelaron la negociación colectiva siguieron registrando tasas de inflación elevadas".

Pero el problema salarios-negociación colectiva-inflación presenta una "doble faz", como expresa con diáfana claridad PLA: "Por un lado, cómo se protege el salario real de los trabajadores en una época de inflación; por otro, cómo repercute la fijación de salarios efectuada por medio de la negociación colectiva en el fenómeno inflacionario". (47)

A menudo se carga tintas en esto último, y no se advierte que más importante es el primero de estos problemas: la protección del salario.

El propio PLA advierte, sin embargo, que "... si bien no es el salario principal causante de la inflación y a través de la política salarial no puede contenerse la inflación, una mala regulación del sistema de fijación de salarios puede contribuir a empujar la inflación./ Esto significa que no es indiferente el tema salario a los efectos de la inflación porque, a través de una política salarial desacertada, inconveniente e irresponsable, puede estimularse la inflación".(48)

Y señala tres ejemplos, contraídos de la experiencia:

“a) La determinaçión parcial y desordenada por gremios genera la tendencia a una agravación de la inflación porque cada aumento de salario provoca un aumento de precios que, a su vez, engendra un nuevo pedido en una carrera desenfrenada y loca. Esos aumentos se acumulan unos a otros y, además, aparecen como estimulándose unos a otros por medio de la imitación y la emulación. ( b) La frecuente y continua fijación de nuevos salarios propicia un clima psicológico propicio a la inflación. $\mathrm{Ni}$ el consumidor se resiste, ni el trabajador tiene reparos en pedir, ni el empresario tiene dificultad para conceder los aumentos, trasladándolos de inmediato a los precios. / c) La determinación de salarios

(47) PLA RODRIGUEZ: Ob. cit.-P. 330.

(48) PLA RODRIGUEZ: Ibid-P. 335. 
con propósitos demagógicos o sin tener la responsabilidad del problema de conjunto, lleva a aumentos desmesurados".(49)

No es, pues, la negociación colectiva un instrumento inerte, totalmente inocente o marginal en el tema de la inflación; sería temerario y hasta pueril negarle toda responsabilidad. De alli que el deslinde del Pla resulta justo y esclarecedor, tanto más con referencia a aquellos países -como son los examinados-donde la negociación se da en forma dispersa y atomizada ya que "una estructura demasiado descentralizada acentúa el predominio de los intereses sectoriales y hace difícil la puesta en práctica de una política de moderación salarial".(50)

Ahora bien, para resolver el crucial problema de la necesaria adecuación de los salarios a las carencias creadas por el proceso inflacionario sólo parecen existir cuatro mecanismos: a) la indexación o indización; b) el aumento por decreto gubernamental; c) el contrato individual; $y, d$ ) la negociación colectiva.

En cuanto a la indexación -sea en forma lineal o más sofisticada como la famosa "scala mobile" italiana, cualquiera sea el sistema que se adopte - constituye un mecanismo automático y, por ello, virtualmente ciego, cuya aplicación escapa de las manos de los protagonistas. Hay virtual unanimidad en adjudicarle efectos inflacionarios por retroalimentación de los precios a través de los costos. La fijación de aumentos por decreto, socorrido sistema en casi toda la Región, peca de rigidez por su generalidad; es materialmente imposible conocer y controlar todas las variables de la urdimbre salarial y, por ello, generalmente se aplican sólo a ciertas categorías salariales, las más bajas. Dejar los reajustes, por último, librados al acuerdo individual es lo mismo que librarlos a la voluntad unilateral del empleador.

Queda sólo la negociación colectiva, entonces, válida no por simple eliminación de alternativas, sino por virtudes y méritos propios, entre los que se destacan su flexibilidad y adaptabilidad, su

(49) PLA RODRIGUEZ: Ibid.-P. 335.

(50) CORDOVA, Efrén: “La inflación. ..".-P. 66. 
carácter bilateral, su rol equilibrador y, sobre todo, su entraña misma compositiva y pacífica que, como bien destaca PLA, respeta la autonomía colectiva y la libertad de las partes.

\section{Productividad}

La conciliación entre las necesidades señaladas de proteger los salarios y no retroalimentar la inflación, sólo parecería viable a través del incremento de la productividad.

El tema ha sido muy poco tratado en la negociación colectiva, en parte por reticencias de los trabajadores que ven en ella un riesgo de sobreexplotación, reducción del salario real y peligro para la estabilidad laboral colectiva, en parte por la renuencia de los empresarios a brindar información o compartir capacidad de decisión.

Un incremento de la productividad, sin embargo, como hace notar un estudio de la revista ANALISIS LABORAL (51), “... no está necesariamente dirigido contra el trabajador, puesto que los beneficios de dicho aumento tienen un efecto variado, y bien podría permitir: a) aumentar las ganancias de la empresa; b) aumentar las ganancias de los trabajadores; c) disminuir los precios; d) reducir las horas de trabajo./ De estos cuatro efectos, tres son favorables al trabajador de manera directa o indirecta (como es el caso de los precios), y es esperable que las comisiones tripartitas, o la propia negociación colectiva puedan generar una distribución razonable de los beneficios que los haga extensibles a todos".

En pro de esta tesis añade: "Los aumentos de sueldos y salarios derivados de la productividad son claramente anti-inflacionarios. Por una parte, es factible realizarlos de manera que su efecto sobre los costos sea reducido, y ello tendría un benéfico efecto multiplicador, por cuanto sabemos que los costos están bastante integrados entre sí. Por otra parte, el aumento en estas condiciones es un efectivo reactivador de la demanda (al aumentar el ingreso real de la población y la retribución del Estado y el capital)

(51) ANALISIS LABORAL 62, Lima agosto 1982.- P. 3. 
y por lo tanto constituirán un reactivante de la producción general./ Con respecto a las condiciones de trabajo: dentro de la variada y diversa extensión de las cláusulas de condiciones de trabajo, las que corresponden a la productividad tienen, en muchos casos, claros aspectos favorables al trabajador. La capacitación profesional, la especialización, el mejoramiento de la maquinaria e instrumental, entre otras, tienen este carácter y pueden administrarse sin que se conviertan en un costo excesivo. De otro lado, todo tipo de mejoramiento técnico puede ser visto como una inversión rentable a la empresa, como también como una transferencia al trabajador, cuyo trabajo a partir de entonces es digno de mejor remuneración; más aún, y esto tal vez sea lo más importante, este mejoramiento de la capacidad productiva del trabajador tiene altas implicancias sociales y humanas".

Es evidente que - a través de la negociación colectiva o fuera de ella- la productividad es de hecho preocupación constante del empresario, la explicación, incluso, y aun la posibilidad de una negociación colectiva sana. "Si la negociación colectiva - dice ARTURO BRONSTEIN (52)- ha permitido democratizar las relaciones laborales y mejorar las condiciones de trabajo, desde el punto de vista de las empresas esto se ha logrado a un costo económico no desdeñable. Como esto no ha significado el derrumbe económico de las empresas, al menos de la mayor parte de éstas, porque la sociedad capitalista sigue funcionando a pesar de sus múltiples problemas, podemos suponer que las empresas han podido pagar ese costo. Pero si lo han podido pagar es sobre todo porque han sabido mejorar su productividad. Aun más, precisamente el hecho de afrontar mayores costos sociales ha sido uno de los más importantes estímulos para los aumentos de productividad al extremo que existe una relación directa entre los costos salariales y las medidas destinadas a mejorar la productividad./ Por lo que se aprecia, existe entonces una relación bastante estrecha entre el mejoramiento de los salarios y las condiciones de trabajo a través de la negociación colectiva y la necesidad de que la empresa mejore su productividad, precisamente para poder pagar esas mejoras. Esto nos lleva a

(52) BRONSTEIN, Arturo: "La productividad en la negociación colectiva internacional", en Análisis Laboral 46, Lima abril 1981.-- P. 5. 
pensar que las discusiones sobre productividad, en principio, deberían formar parte de las negociaciones colectivas".

Ello habría de motivar a la larga un cambio de actitud de los interlocutores. "Por parte de los trabajadores, parece existir la convicción de que ahora es necesario negociar sobre la productividad, precisamente porque el mejoramiento de la productividad es prácticamente la única condición que les permitirá asegurarse que las ventajas que consiguen a través de la negociación colectiva no serán efímeras".(53)

"La relación que se establece entre incrementos de salarios y aumentos de productividad tiene ventajas sobre otras posibles opciones -dice un estudio de la OIT (54). Permite, por ejemplo, elegir entre varias alternativas en cuanto a aumentos de salarios y de ocupación. En una situación de alto desempleo, los aumentos previsibles del producto podrían orientarse preferentemente a incrementar la ocupación más que a mejorar las remuneraciones reales medias; en cambio, si el desempleo no es elevado, bastaría con orientar una parte del crecimiento esperado para absorver el aumento de la fuerza de trabajo, y el resto podría orientarse a mejorar las remuneraciones reales. Por otra parte, este criterio contribuye a mantener la participación de los trabajadores en el producto y en el ingreso, aún en situaciones recesivas".

Aunque de nula vigencia en los países de la región bajo estudio, los problemas de productividad sí son abordados entre otros paises en desarrollo. BRONSTEIN alude a Zambia en Africa y Singapur en Asia; en el primero de estos países; “... una Conferencia Tripartita de Trabajo adoptó en 1967 un Código para fomentar la productividad que contiene algunos principios sencillos que pueden ser aplicados directamente por cualquier empresa. Este Código destaca algunos de los factores más elementales que pueden mejorar o perjudicar la productividad: entre los primeros figura un sistema de incentivos vinculados al rendimiento, mejores condiciones de trabajo, seguridad en el empleo, trato equitativo de

(53) BRONSTEIN: Ibid.-P. 6.

(54) BRONSTEIN, en Análisis Laboral 47, Lima mayo 1981.- P. 13. 
los trabajadores. Entre los segundos se menciona al ausentismo, la falta de puntualidad, la embriaguez, el 'dormir voluntariamente durante las horas de trabajo', pero también la 'inadecuada selección de supervisores" ".(55)

\section{La dimensión social}

"En los países en vías de desarrollo, la política de salarios (. . .) debe encaminarse a asegurar el crecimiento económico nacional, la reducción de los desniveles sociales y económicos, y las desigualdades de todo género que existen entre los diversos integrantes de la comunidad", dice HERNANDEZ RUEDA (56); y añade: "Toda política salarial, debe, pues, perseguir necesariamente la seguridad económica, sin la cual no existe la paz social, objetivo obligado de las relaciones laborales en toda época".(57)

¿Es el convenio colectivo, realmente, un mecanismo de redistribución de ingresos? La OIT (58) examina esa cuestión y sus posibles efectos sobre el comportamiento de ciertas variables macroeconómicas, como el consumo, el ahorro, la inversión y el crecimiento económico en general, y concluye que, "en el contexto de la economía en vías de desarrollo de América Latina y el Caribe, es fundamental recordar que, a pesar de la considerable expansión de la negociación colectiva en los últimos años, en la mayor parte de los países del continente los convenios colectivos amparan a un porcentaje bastante bajo de la población económicamente activa". Siendo, pues, limitado el universo y concentrado en sectores de gran valor productivo pero reducida población laboral, hecho que limita la negociación colectiva a un segmento comparativamente pequeño de la población activa. "Hay que mostrarse muy prudente acerca de toda idea relativa al posible impacto de la redistribución operada por la sola negociación colectiva

(55) Cit., por HERNANDEZ RUEDA: Ob. cit.-P. 259.

(56) HERNANDEZ RUEDA: Ibid.-P. 266.

(57) HERNANDEZ RUEDA: I bid.-P. 258.

(58) OIT: "Relaciones. ..", Informe III.- P. 41. 
sobre las grandes variables macroeconómicas, tales como el consumo, el ahorro, la inversión y el crecimiento económico en general".

Pero la negociación colectiva actúa decisivamente en pro de la elevación del nivel y la calidad de vida, no sólo de los directamente involucrados en sus efectos, sino en el estímulo de la legislación protectora de sectores más vastos de la población. No es infrecuente que beneficios que aparecieron por primera vez en los convenios 'de punta' se extiendan después, en cascada, de las empresas grandes a las medianas y de éstas a la legislación laboral común.

La negociación aporta, por otra parte, una valiosa cuota de legitimidad social a las conquistas de los trabajadores, más aún si advertimos que "la remuneración justa del trabajador no depende de la generosidad del empleador, sino más bien del derecho a asociarse en sindicatos, consagrado y protegido constitucionalmente. Los sindicatos de trabajadores constituyen un elemento indispensable para la vida social, un instrumento eficaz para el logro del equilibrio económico, el bien común y la justicia social".(59)

\section{El Convenio Colectivo y la Administración Empresarial}

En algunos países del área -Panamá, República Dominicanala negociación salarial respeta y hasta promueve una política de remuneraciones en función de puestos de trabajo. El CT de Panamá incluso imponía como una cláusula obligatoria la "clasificación de puestos", que en la actualidad es una cláusula facultativa. En República Dominicana es también práctica corriente discutir y convenir una clasificación de puestos a objeto de establecer la escala de aumentos de salarios y los reajustes pertinentes.(60)

En el Perú, en cambio, por una perniciosa costumbre ampliamente generalizada, los aumentos salariales se negocian por canti-

(59) HERNANDEZ RUEDA: Ob. cit.- P. 262.

(60) Vid. MURGAS: Ob. cit.- P. 157: y HERNANDEZ RUEDA, Lupo: "Procedimiento y estructura de la negociación colectiva a nivel de la empresa y del establecimiento", Informe nacional presentado al XI Congreso Internacional, Caracas 1985, Vol. I, P. 569. 
dad única, igual para todos, cuyo efecto es achatar la curva salarial y aproximar progresivamente los extremos, con ventaja innegable para los de menor remuneración pero tremendamente depresiva para los más calificados. Se ha llegado al extremo, en algunas empresas públicas, de pactar incrementos automáticos consistentes en la aplicación del índice de precios al consumidor, no sobre el salario directo individual, sino sobre el promedio salarial, de modo que todos aquellos remunerados por debajo del promedio perciben aumentos necesariamente superiores a la inflación, en tanto que los de ingreso superior jamás podrían recuperar el deterioro causado por aquélla.

Es considerable el impacto que una buena o una mala contratación colectiva puede tener en la administración empresarial. Cuando una práctica errónea se hace universal, el efecto traspasa al conjunto de la economia nacional.

\section{CONCLUSIONES}

\section{Primera}

La negociación colectiva en el área regional examinada - Ecuador y Perú, América Central y el Caribe- presenta características comunes a la mayoría de países, algunas de ellas contradictorias entre sí:

1. Es marcadamente conflictual, a pesar de estar muy institucionalizada a través de procedimientos formales.

2. Tiene poca difusión en términos cuantitativos, pero importante incidencia cualitativa, por radicar en los estratos laborales más destacados.

3. Acusa un acentuado intervencionismo estatal, pero también una clara tendencia a la búsqueda de grados más amplios de autonomía.

Su principal característica, sin embargo, es darse casi exclusivamente a nivel de empresa, con contadas excepciones de negociación por rama de actividad. 


\section{Segunda}

El convenio colectivo y la economía se ejercen directa y recíproca influencia.

De los diversos condicionamientos a la negociación colectiva, más incide lo económico que lo político, lo jurídico o lo social, salvedad hecha, naturalmente, de los casos extremos de suspensión o restricción de las negociación colectiva por disposición legislativa o gubernamental.

A su vez, el convenio colectivo cumple un importante rol a nivel macro y microeconómico.

\section{Tercera}

El que el ámbito del convenio se dé en la empresa o establecimiento determina algunos efectos muy resaltantes:

1. Favorece a los trabajadores de las empresas más grandes y sofisticadas, pero margina a los que pertenecen a empresas medianas y pequeñas, que son mayoría, acentuando así desequilibrios salariales y sociales.

2. Disminuye su impacto social y económico en la dimensión nacional.

3. Debilita el rol redistributivo que podría cumplir como instrumento de una política de rentas o económica en general.

\section{Cuarta}

No parecen justificadas las acusaciones de que la negociación colectiva provoca o, al menos, impulsa la inflación. Por lo general, los reajustes salariales por vías de negociación son el efecto y no la causa del alza de los precios.

Ello no obstante, si los incrementos salariales son trasladados a los precios, lo que sucede más fácilmente en una negociación descentralizada, tales incrementos pueden actuar como retroaliementadores de la inflación. 
Las experiencias concretas en la Región demuestran que ni la suspensión de la negociación colectiva ni la limitación de los salarios tienen eficacia en la lucha contra la inflación.

Paradójicamente, algunos planes políticos heterodoxos han tenido éxito - al menos temporal- contra la inflación sin recurrir a contenciones salariales.

Sexta

Es importante estimular la inclusión dentro de la negociación colectiva del tema de la productividad, que es, sin duda, la manera más certera de permitir el acrecimiento de los salarios reales sin provocar secuelas inflacionarias. 